\title{
Deep frying: the role of water from food being fried and acrylamide formation
}

Oléagineux, Corps Gras, Lipides. Volume 10, Numéro 4, 297-303, JUILLET-AOÛT 2003, Problématiques actuelles dans le domaine de l'analyse des oléagineux et des corps gras

\author{
Auteur(s) : Christian GERTZ ${ }^{1}$, S. KLOSTERMANN ${ }^{1}$, S. Parkash KOCHHAR ${ }^{2}$ \\ ${ }^{1}$ Chemisches Untersuchungsamt Hagen, Pappelstrasse 1, D-58099 Hagen, Germany \\ <gertz@cua-hagen.de> \\ ${ }^{2}$ SPK Consultancy Services, 14 Holmemoor Drive, Sonning, Reading, RG4 6TE, United Kingdom \\ <spkochhar-99@yahoo.co.uk
}

Summary : The formation of acrylamide during food frying is generally influenced by food type, thermal treatment and equipment. The acrylamide concentration is increased when frying oils containing a higher level of polar materials or silicone or larger amounts of diglycerides. This effect may be caused by moisture escaping from food that has an enhancing effect on the heat transfer. It was noticed that if the moisture in the frying operation was bound by special adsorbents, the acrylamide content could be reduced by more than $50 \%$. The effects of several additives like citric acid on the formation of acrylamide during frying of chips were also investigated. The mechanism of acrylamide formation in fried foods is discussed to explain these findings.

Keywords : acrylamide, deep-frying, polar material, moisture

\section{ARTICLE}

Acrylamide is a rather reactive substance that is supposed to be genotoxic and cancerogenic because of animal tests. It can react by both ionic and free radical mechanism and its presence in free form in food was therefore unexpected. Since last year, when it became known that acrylamide is formed predominantly in starchy and carbohydrate-rich foods during preparation at high temperature, this toxicant has drawn the attention of the public and many researchers. When calculating the Margin of Exposure (MOE, lowest cancerogenic dose in animals divided by daily uptake by man), acrylamide is rated 1000, whereas aflatoxins and nitrosamines each have a value of 100,000, thus being 100 times less dangerous. For comparison, the World Health Organisation have set a drinking water limit of $0.5 \mu \mathrm{g} / \mathrm{kg}$ for many countries (WHO 1985, 1996) and in Europe the recommended limit is set to be lowered to $0.1 \mu \mathrm{g} / \mathrm{kg}$ in 2003 (EEC 1998). Therefore, concern appears to be justified.

During the last $3^{\text {rd }}$ symposium on Deep Fat Frying in Germany in March 2000, one of the eight recommendations [1] made by the experts was :

"Encourage and support basic research focused on understanding the dynamics of deep fat frying and frying process. Research should be cross-disciplinary encompassing oil chemistry, food engineering, sensory science, food chemistry and nutritional sciences". 
It was a great mistake to ignore this recommendation by carrying out no basic research on the chemistry and dynamics of deep-frying. When the acrylamide problem first came up by the publication of a study by Sweden's National Food Administration, April 2002, the industry was shocked and surprised. Initially some of the experts in the field did not even believe or tried to ignore it by expressing doubts in the correctness of the results. But now everybody realises that the results were correct and the applied analytical methods were appropriate [2]. Nevertheless, more fundamental research is needed to understand the formation of acrylamide in foods during frying, baking or cooking at high temperature.

\section{Materials and methods}

The method for the preparation of the samples and the determination of acrylamide by gas chromatography - mass spectrometry method with deuterated acrylamide was described previously. The detection limit of this method in French fries was $10 \mu \mathrm{g} / \mathrm{kg}$, the repeatability of the analytical procedure was $4.8 \%$ (300 $\mu \mathrm{g} / \mathrm{kg}$ acrylamide), expressed as the coefficient of standard deviation. The recovery of acrylamide obtained by this method ranged between $95-103 \%$. This GC-MS method is very sensitive and specific, has a high repeatability but is very time-consuming and labour-expensive. Nowadays, analysing matrices like French fries or bakery products the LC-MS/MS methodology $[4,5]$ is preferred making a water extract of the food and testing the extract by LC-MS/MS with deuterated or carbon labelled acrylamide as the internal standard. Detection is by positive electrospray ionisation, monitoring transition $\mathrm{m} / \mathrm{z} 72$ to 55 . In 2002, when we made the first trials with acrylamide, the LC-MS/MS equipment was not yet available in our laboratory.

\section{Frying experiments}

$40 \mathrm{~g}$ and $100 \mathrm{~g}$ of pre-fried French fries were cooked in a frier filled with 2,5 litre of vegetable oil for 2,5 and 3,5 min, the size of the pre-fried French fries : $10 \times 10 \mathrm{~mm}$ and various lengths.

\section{Discussion}

Temperature more than $120^{\circ} \mathrm{C}$ is seen as a main cause for the formation of acrylamide in starchy foods because of non enzymatic browning, known as Maillard reaction. Products of the Maillard reaction are responsible for much of the flavour and colour generated during heating at elevated temperature. The acrylamide concentrations in French fries heated at $170^{\circ} \mathrm{C}$ for $2.5 \mathrm{~min}$ were too low to obtain significant differences. Heating time of 3.5 or temperature of $180^{\circ} \mathrm{C}$ provided clear results. The results (figure 1) show that the formation of acrylamide is accelerated above $175^{\circ} \mathrm{C}[3$, 21]. The same effect was observed using other oils for frying (figure 2). These findings published in September 2002 [3] were confirmed by other investigations. Therefore, the German Health authorities [6] recommended in December 2002 to fry French fries and other starchy foods below $175^{\circ} \mathrm{C}$. It is believed that the temperature and duration of the heat treatment are most critical factors of acrylamide formation. This statement simplifies the process of acrylamide formation assuming that specific heat and thermal conductivity - the rate at which energy is transferred to the food surface - are constant and the sort of oil or the state of oil degradation has no influence. Frying is basically a dehydration process in which oil acts as transfer medium for heat. After food immersion into the oil, a sharp superficial region is immediately formed. The thickness of this region is about $0.3 \mathrm{~mm}$ [7]. The temperature within this region is equal to the frying temperature. After boundary zone is dehydrated, water migrates from the central position of the food radially outward 
to the walls to replace what is lost during heating. Behind this front the temperature within the food is about $100-104{ }^{\circ} \mathrm{C}$, representing the temperature of the change from water to steam. The vapour pressure within the food is constantly high [8] and falls within in this crust leaving the food into the surrounding oil. Finally, no more moisture can leave the food. When the food is overcooked the capillary bound water also leaves the food. Finally, the food gets dry and becomes hollow inside. This concept explains why increasing the frying temperature does not cook the food quicker. Acrylamide or its precursors which have been formed are stripped out of the crust by water escaping form the food as steam limited by the porosity of the crust or capillary of the matrix. When the vapour pressure drops because of loss of unbound water within the food, acrylamide remains bound in the crust and excessive darkening and drying of the surface do not occur. Oil and water are immiscible. For frying to occur, heat must be transferred from the non-aqueous medium, oil, into the mostly aqueous medium, food.

The heat transfer or cooking ability of the oil, including at the oil-food interface, must result from both degradation products and the fat composition, containing polar compounds. The causes of increasing oil contact with water food are water-activated surfactants and lipid-activated surfactants ("Surfactant theory of frying") [9, 10]. Blumenthal [10] found out that the contact time in fresh oil and much abused oil changes from $10 \%$ to $80 \%$ of the immersion time. Fat components of the fresh or degrading oil which affect the heat transfer at the food interface must act to reduce the interfacial tension between the food surface containing water and oil. Soaps (salts of fatty acids) form inverted micelles water in oil emulsion. Used frying oil may contain 0.3-1.5\% water at frying temperatures. Figure 2 shows that different oils and fats have a different ability to transfer the heat to the food because they contain different quantities of substances such as mono- and diglycerides, short or middle chain fatty acids reducing the surface tension. The formation of acrylamide in food was much higher when using palm olein or lard. Two types of palm olein, and in a mixture of palm olein with other vegetable oils show the level of acrylamide increasing with palm oil products. This may be due to the presence of $6-8 \%$ of diglycerides in the tested palm oleins. Tallow, containing middle chain fatty acids, gives much higher level of acrylamide in comparison to vegetable oils like sunflower or rapeseed oil. Increased surfactant levels cause longer contact times between the hot oil and aqueous food surfaces. More heat can be transferred from oil to food in a fixed period of time. In fresh oil there is very little that will allow the oil to cling to the exterior of the food against the gradient of steam escaping. Matthäus [11] published data to investigate the dependency from the sort of oil and the formation of acrylamide. Unfortunately, further details about the frying conditions and composition of the tested oils are missing. The ranges and the means of acrylamide level in the fried products obtained after 5 sequent frying processes very different, he concluded that the sort of deep frying oil or silicone has no influence on the formation of acrylamide during frying process (figure 3). The better heat transfer in palm olein or tallow (figure 2) may explain the decreasing acrylamide level at $180^{\circ} \mathrm{C}$ compared to sunflower. Obviously, the decomposition of acrylamide starts under frying conditions already at $180^{\circ} \mathrm{C}$ (table 1 ), if the heat transfer is more intense. 
Table 1 Decomposition and formation of acrylamide during heating in different media

\begin{tabular}{l|l|l|l}
\hline & Maximum & \multicolumn{1}{l}{ Start of decomposition } & \\
\hline Water (Steam) & $120^{\circ} \mathrm{C}$ & $160^{\circ} \mathrm{C}$ & $180{ }^{\circ} \mathrm{C}$ \\
\hline Fat/Oil & $150{ }^{\circ} \mathrm{C}$ & $185^{\circ} \mathrm{C}$ & $205^{\circ} \mathrm{C}$ \\
\hline Air & $180^{\circ} \mathrm{C}$ & $225^{\circ} \mathrm{C}$ & $240{ }^{\circ} \mathrm{C}$ \\
\hline
\end{tabular}

Silicone legally permitted in Europe as additive E900 is often used as antifoaming agent in frying oils and fats. It is supposed that the monomolecular layer at the surface may hinder or reduce the evaporation of water-steam. Thus the addition of silicone may have an influence on acrylamide level, too (figure 4). Franke et al. [13] used deep frying oil containing silicone. Every 10 minutes a certain quantity of French fries was produced at $168^{\circ} \mathrm{C}$. The acrylamide levels increased within the first 5 frying procedures from $130 \mu \mathrm{g} / \mathrm{kg}$ up to a constant level of $350 \mu \mathrm{g} / \mathrm{kg}$. We repeated the test with the same oil at $170^{\circ} \mathrm{C}$ but changing the intervals (figure 5). The water content of the fresh oil was less $0.1 \%$, after the first frying $0.3 \%$ and increased to $0.65 \%$ after a sequence of 4 frying procedures. After a period of $60 \mathrm{~min}$ without immersing food, the water content decrease to $0.4 \%$. Fresh oil does not yet contain enough polar compounds acting as surfactant which can bound the water in the frying oil for a longer period of time. Analysing used frying fats with $15 \%$ respectively $45 \%$ polar materials $0.4 \%$ respectively $0.65 \%$ water content was found. Obviously, bounded water in deep frying oils enhances the heat transfer while even traces of water improve the heat conductivity (table 2). The same effect is observed preparing increasing quantities of French fries. The formation of acrylamide is reduced to the half when the moisture in the frying oil is partially bounded by the addition of drying filter aid (figure 6).

Table 2 Specific heats of different food ingredients [22]

\begin{tabular}{|l|l|l|l|l|l|}
\hline Specific heat $\left(\mathbf{k j} / \mathbf{k g}\right.$ per $\left.{ }^{\circ} \mathbf{K}\right)$ & \multicolumn{2}{l}{} \\
\hline Water & 4.18 \\
\hline Protein & 1.55 \\
\hline Fat & 1.67 \\
\hline Carbohydrate & 1.42 \\
\hline
\end{tabular}

In practice, changes in the cooked food quality are observed even if there are no changes in the processing parameters (equipment, type of oil, temperature, and heating time) due to the degradation in the frying oil. During breakdown or interaction of the oil with food more surfactants are formed, causing a better interaction food and oil, which are normally immiscible materials [11]. The degradation products and agent like silicone changing the physical properties of the frying oil must have an influence on the heat transfer and furthermore on the acrylamide contamination. 


\section{Mechanism of the formation of acrylamide}

A number of theories have been proposed to account for the mechanism by which acrylamide is formed in fried food. In experiments with radio-labeled asparagine it has been confirmed that previously asparagine is the nitrogen source for acrylamide. Asparagine is found abundantly in wheat, corn, potatoes, green beans and peanuts. The heating of asparagine alone does not efficiently produce acrylamide, but combined with reducing sugars like glucose and fructose the formation of acrylamide is accelerated. Other factors, which influence the reaction may include potato variety, temperature, product moisture and $\mathrm{pH}$. In the discussion about possible pathways of the formation of acrylamide in deep frying products, it was firstly assumed that acrylamide is formed via glycerol by oxidation of acrolein to acrylic acid which reacts with ammonium coming from amino acids (figure 7a). Glycerol should be formed by hydrolysis of triacylglycerides. In used deep frying fats no significant variations were found for mono- and diglyceride concentrations throughout the successive frying. An increase in the area of the diglyceride peak can be explained by an oxidative degradation of polyunsaturated fatty acids producing more volatile fatty acids like octanoate (C8:0) and heptanoate $(\mathrm{C} 7: 0)$. The remaining molecule of triacylglycerol contains the fragment at the position $1 \mathrm{n}$ and $3 \mathrm{n}$ resulting in a lower molecular mass which is now equal to diacylgylcerol. No free glycerol is formed which could act as a precursor of acrylamide [14]. Another possible mechanism describes that acrylic acid arises directly from the decomposition of two common amino acids, alanin and aspartic acid. Acrolein is also being formed in various concentrations in the pyrolysis of triglycerides (not via glycerol) and depending on the kind of cooking oil heated and the temperature applied to the oil [15].

From the fat chemistry, it is well known that monoacylglycerols decompose above $150{ }^{\circ} \mathrm{C}$ in a cyclic reaction to an olefine (acrolein) and a free fatty acid. The same mechanism may explain the immediate formation of acrolein by heating mono acylglycerols (figure 7b). It is expected [16] that in meat or bakery products acrylamide disappear at a rather high rate, presumably through bonding to reactive constituents. The elimination may even occur at such a high rate that no relevant acrylamide concentration build up or destroyed immediately after it is formed. It is generally accepted that the first stage of the actual Maillard reaction is the condensation of unprotonated amino group with reducing sugar in the open chain form resulting in a Schiff's base glycosylamine [17]. The rate of reaction between sugars and amino groups of amino acids is maximal at weakly acidic $\mathrm{pH}$. The $\mathrm{pKb}$ of asparagine is 8.8 and the lowest of all amino acids. More probably, at the pH in meat the other amino acids get more and more reactive than asparagine, not forming acrylamide. It is also possible that the low $\mathrm{pH}$ in a fryer induced the splitting of glucose or fructose in two triose glycerine-aldehyde and dihydroxyacetone following a reverse aldol condensation as the heat causes a decrease of $\mathrm{pH}$ because of higher water dissociation and water activity in the crust. The reaction of asparagine with fructose via dihydroxy acetone (figure 7c) is quicker than with glucose via glycerolaldehyde. Weisshaar et al. [18] found that the acrylamide formation is more accelerated in presence of silica gel as an acid medium (table 3) than in starch as carrier. Biedermann et al. [19] found that higher concentration of sodium carbonate $(\mathrm{pH}>9)$ decreased the acrylamide concentration even in presence of fructose. Otherwise, the reduction of browning when organic acids are added could be attributed to the inhibitory effect of acidic $\mathrm{pH}$ on the development of non-enzymatic alkaline catalysed browning [20]. Therefore, it may be possible that citric acid or frying oil improving agents containing citric acid like Maxfry classic induce a decrease of the acrylamide concentration if it is added to the frying oil at higher levels (table 3 ). 
Table 3 Acrylamide formation by heating asparagines with no additional nitrogen source $\left(170{ }^{\circ} \mathrm{C}\right.$, $60 \mathrm{~min}$, test substance $+5 \mathrm{~g}$ carrier substance (starch or silica gel) $+10 \mathrm{~g}$ water [18].

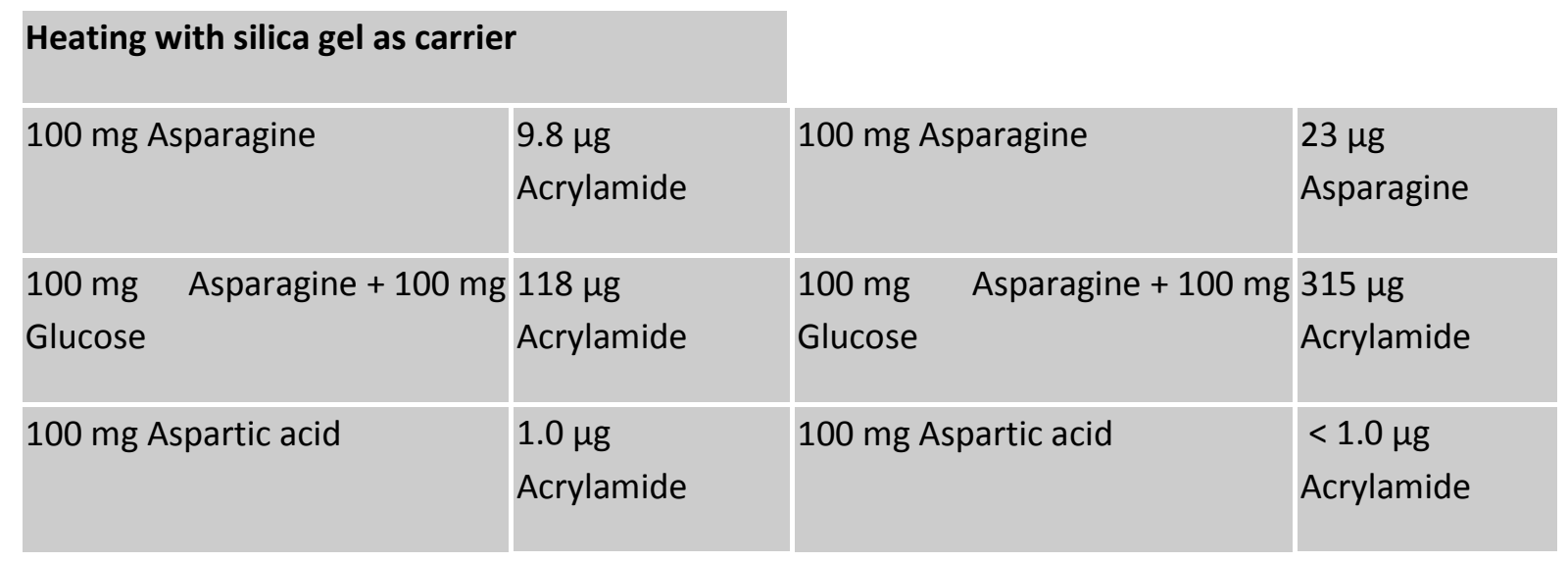

Some authors studied the formation of acrylamide in various browning model systems [18, 19, 21]. When asparagine as nitrogen source was reacted at $170^{\circ} \mathrm{C}$ or $180^{\circ} \mathrm{C}$ with fructose, glucose, acrylic acid or dihydroxy acetone, very high levels of acrylamide were formed whereas asparagine did not produce detectable amounts of acrylamide with ethylenglycole. Also, when ammonium chloride or asparagine were heated with triolein, glycerol or acrolein, only low levels of acrylamide were formed. By repeating the heating experiments of organic acids (lactic, malic, citric acid) with asparagines as nitrogen source, the formation of acrylamide was very low or zero. Heating experiments with amino acids like cysteine, aspargic acid or valine show no effect or result even in a slight reduction of acrylamide concentration Relatively high levels of acrylamide were formed from ammonia in combination with acrolein or acrylic acid whereas ammonium chloride and acrolein did not produce detectable amounts of acrylamide. The most important reaction is the splitting of glucose or fructose forming dihydroxy acetone or glyceraldehyde and finally acrylic acid. Reaction products containing 3 carbons like glycerol (from triglycerides), propionaldehyde, methylglyoxal and acrolein can be excluded as precursors. Obiously, asparagine seems to work as a nitrogen source and to form acrylamide at the same time as presumed in figure $7 d[18]$.

\section{Conclusions}

The role of water from food being fried during the mass-heat-transfer is more important than one believed.

The acrylamide formation depends on many conditions, the most important ones being heat transfer, which is a function of temperature and heat conductivity of the heating medium (air, fat and water) heating time, water activity and $\mathrm{pH}$ and concentration of amino and carbonyl reactant.

Formation of acrylamide can be decreased in fried food by lowering frying temperature below $175^{\circ} \mathrm{C}$. But lowering frying temperature does not necessarily reduce acrylamide concentration in fried products while all process parameters need to be included to be taken into account. 
The type of frying oil used may have a significant effect on the level of acrylamide contamination in fried food.

Surprisingly, palm oil products used for frying gave higher level of acrylamide formation. This is probably due to emulsification action of higher amount of diacylglycerols present. Further research is needed to prove these findings.

Frying oils and fats without additive of permitted anti-foaming agent, silicones $E$ 900, result in lower level of acrylamide formation.

\section{RÉFÉRENCES}

1. $3^{\text {rd }}$ International Symposium in Deep-Frying Recommendations. Eur J Lipid Sci Technol $2000 ; 102$ : 594.

2. AHN JS, CASTLE L, CLARKE DB, LLOYD AS, PHILO MR, SPECK DR. Verification of the findings of acrylamide in heated foods. Food Additives and Contaminants $2002 ; 19: 1116-24$.

3. GERTZ CH, KLOSTERMANN S. Analysis of acrylamide and mechanisms of its formation in deep-fried products. Eur J Lipid Sci Technol $2002 ; 104: 762-71$.

4. ONO H, CHUDA Y, OHNISHI-KAMEYAMA M, YADA H, ISHIZAKA M, KOBAYASHI H, YOSHIDA M. Analysis of acryl amide by LC-MS/MS and GC-MS in processed Japanese foods. Food Additives and Contaminants $2003 ; 20: 215-20$.

5. ROSÉN J, HELLENAS K. Analysis of acrylamide in cooked foods by liquid chromatography tandem mass spectrometry. Analyst $2002 ; 127: 880-2$.

6. Bundesministerium fr Verbraucherschutz, Ernährung und Landwirtschaft (2002). Pressemitteilung Nummer 374 v. 20.12.2002.

7. NGADI MO, WATTS KC., CORREIA LR. Finite element method modelling transfer in chicken drum during deep fat frying. Journal of Food Engineering 1997 ; 32 : 11-20.

8. VITRAC O, TRYSTRAM G, RAULT-WACK AL. Deep-fat frying of food : heat and mass transfer, transformations and reactions inside the frying material. Eur J Lipid Sc Technol $2000 ; 102: 529-38$.

9. OHLSEN R (1983). Structure and physical, properties of fats. In : Dietary Fats and Health. Ed. E.G. Perkins and W.J. Visek p. 44 Amer. Oil Chem. Soc., Champaign. I 11.

10. BLUMENTHAL M. Optimum Frying : Theory and Practice. Monograph series, Libra Laboratories, Inc. Piscatawy, N.J. 1988.

11. MATTHAEUS B, VOSSMANN K, HAASE NU. Pommes Frites : Einflussmöglichkeiten auf den Acrylamidgehalt AID $2003 ; 3: 235-9$.

12. MOTTRAM DS, BRONISLAW LW, DODSON AT. Acrylamide is formed in the Maillard reaction. Nature 2002 ; 418 : 49. 
13. FRANKE K, KREYENMEIER F, REIMERDES EH. Ganzheitlicher Ansatz- Acrylamid- das gesamte Geschehen um die Bildung ist entscheidend. Lebensmitteltechnik $2003 ; 35: 60-2$.

14. MÁRQUEZ-RUIZ G, DOBARGANES MC. Short-chain fatty acid formation during thermo-oxidation and frying. J Sci Food Agr $1996 ; 70: 120-6$.

15. LIN S, LIOU SJ. Aliphatic Aldehydes Produced by Heating Chinese Cooking. Bull Environ Contam Toxicol $2000 ; 64: 817-24$.

16. BIEDERMANN E, BIEDERMANN-BREM S, NOTI A, GROB K. Acrylamide formation and possibilities to decrease the potential of acrylamide formation in potatoes. Mitt Lebensm Hyg $2002 ; 93$ : 638-52.

17. VAN BOEKEL MAJS. Kinetic aspects of the Maillard reaction : A critical review. Nahrung/Food $2001 ; 45: 150-9$.

18. WEISSHAAR R, GUTSCHE B. Formation of acrylamide in heated potato products - model experiments pointing to asparagine as precursor. Deutsche Lebensmittel-Rundschau 2002 ; 98 : 397401.

19. BIEDERMANN M, BIEDERMANN-BREM S, NOTI A, GROB K. Methods for determining the potential of acrylamide formation and its elimination in raw materials for food preparation, such as potatoes. Mitt Lebensm Hygiene 2002 ; 93 : 653-67.

20. ONIGBINDE AO, ONABUN V. Effect of $\mathrm{pH}$ on the cooking properties of cowpeas. Food Chemistry $1993 ; 47: 125-7$.

21. YASUHARA A, TANAKA Y, HENGEL M, SHIBAMOTO T. Gas chromatographic investigation of acrylamide formation in browning model systems. J Agric Food Chem $2003 ; 51$ : 3999-4003.

22. SAHIN S, SASTRY SK, BAYRINDIRLI L. The determination of convective heat transfer coefficient during frying. Journal of Food Engineering 1999 ; 39 : 307-11. n

Heating with search as carrier

Component

Medium of Heat Transfer 
Illustrations

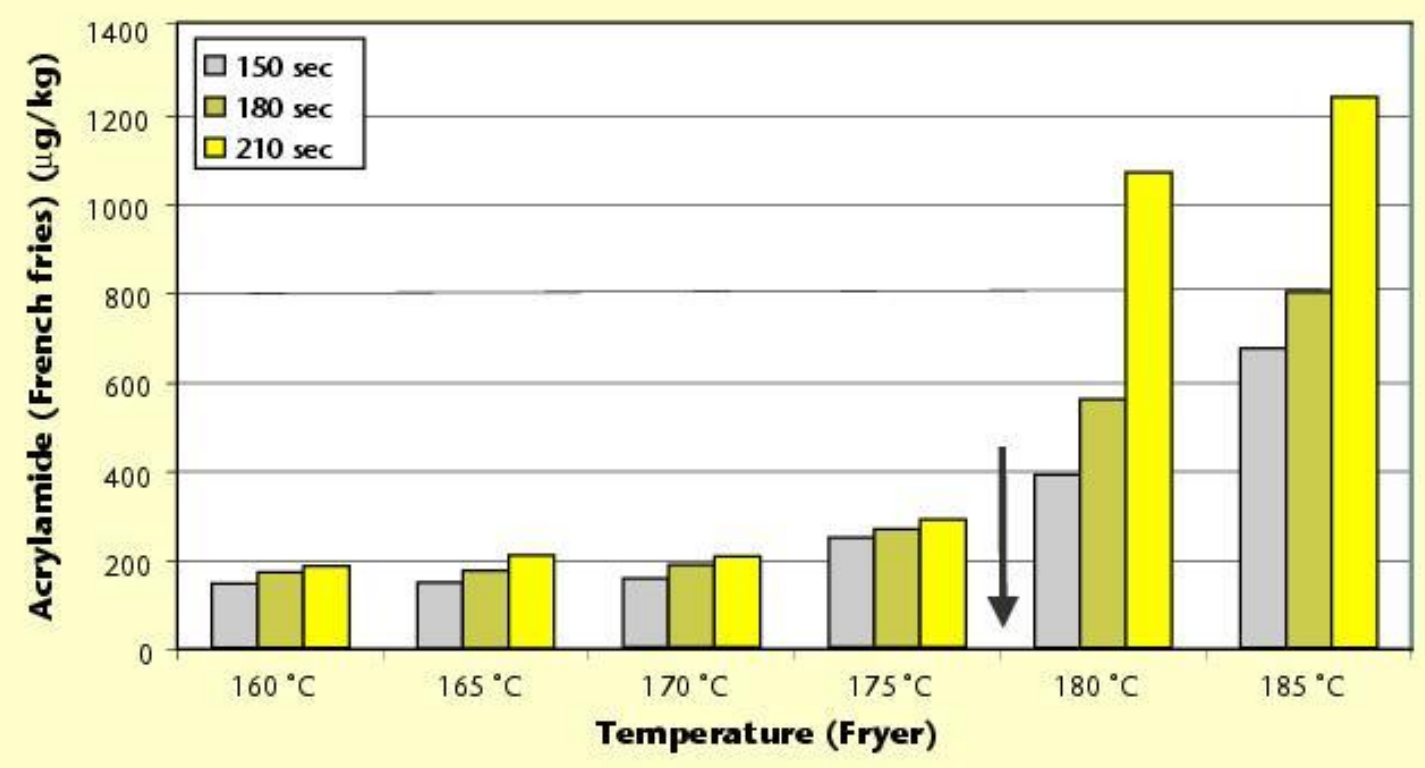

Figure 1. Acrylamide formation during deep-frying (40 g, rapeseed oil) at different temperatures.

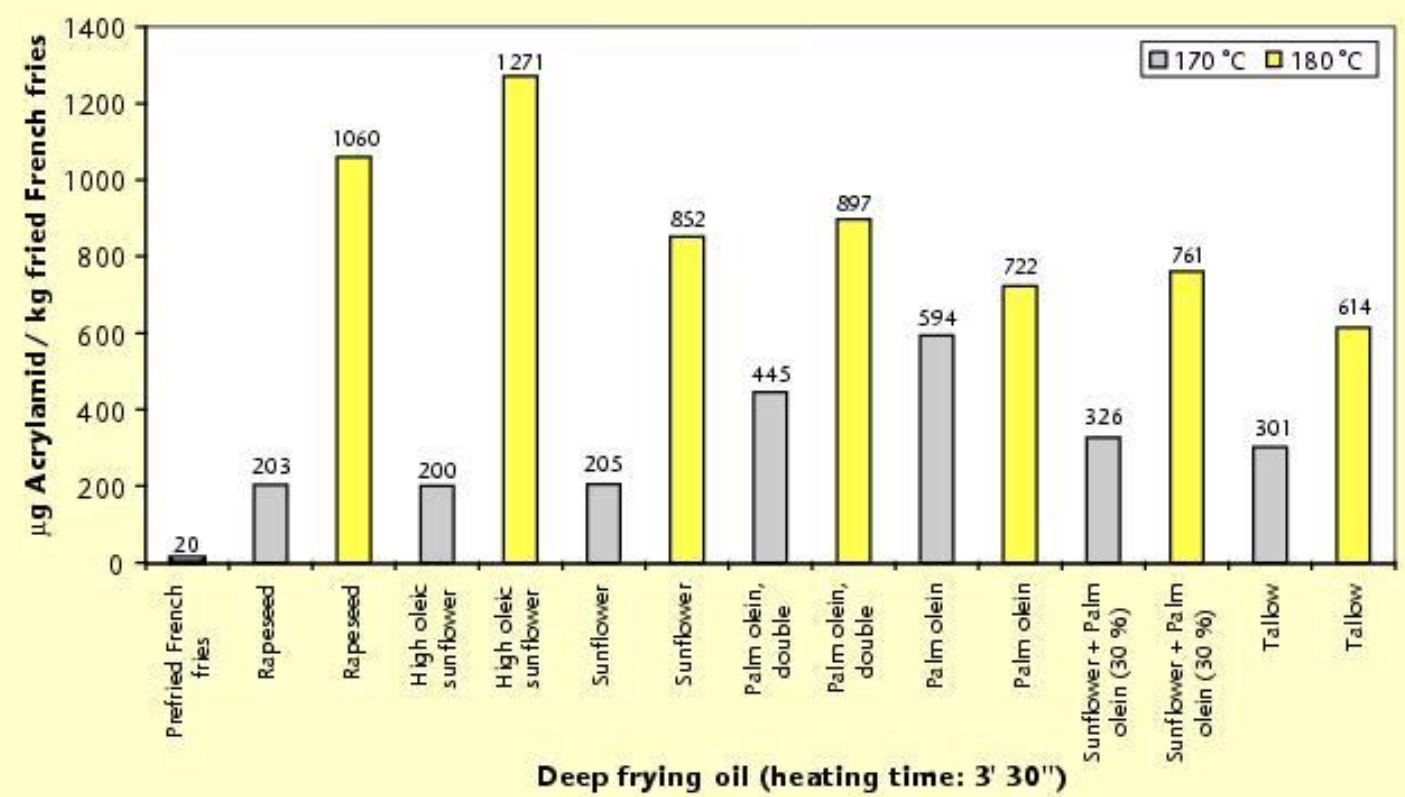

Figure 2. Acrylamide formation in different fats and oils during deep-frying $(40 \mathrm{~g})$ at $170^{\circ} \mathrm{C}$ and $180^{\circ} \mathrm{C}$. 


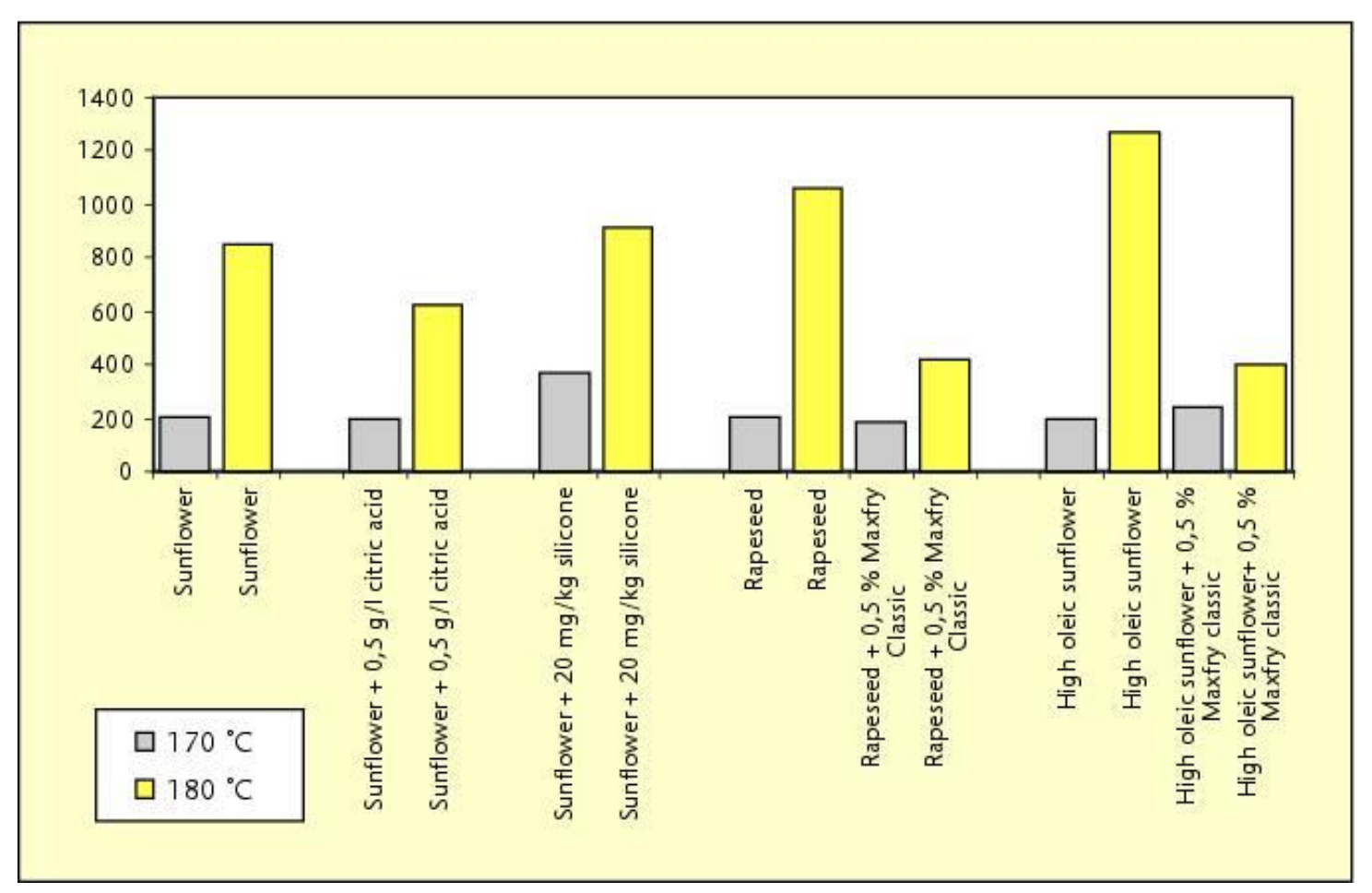

Figure 3. The influence of silicone, citric acid and other additives on the formation of acrylamide during deep frying of French fries $\left(170^{\circ} \mathrm{C}, 180^{\circ} \mathrm{C}\right), 3.30 \mathrm{sec}$.

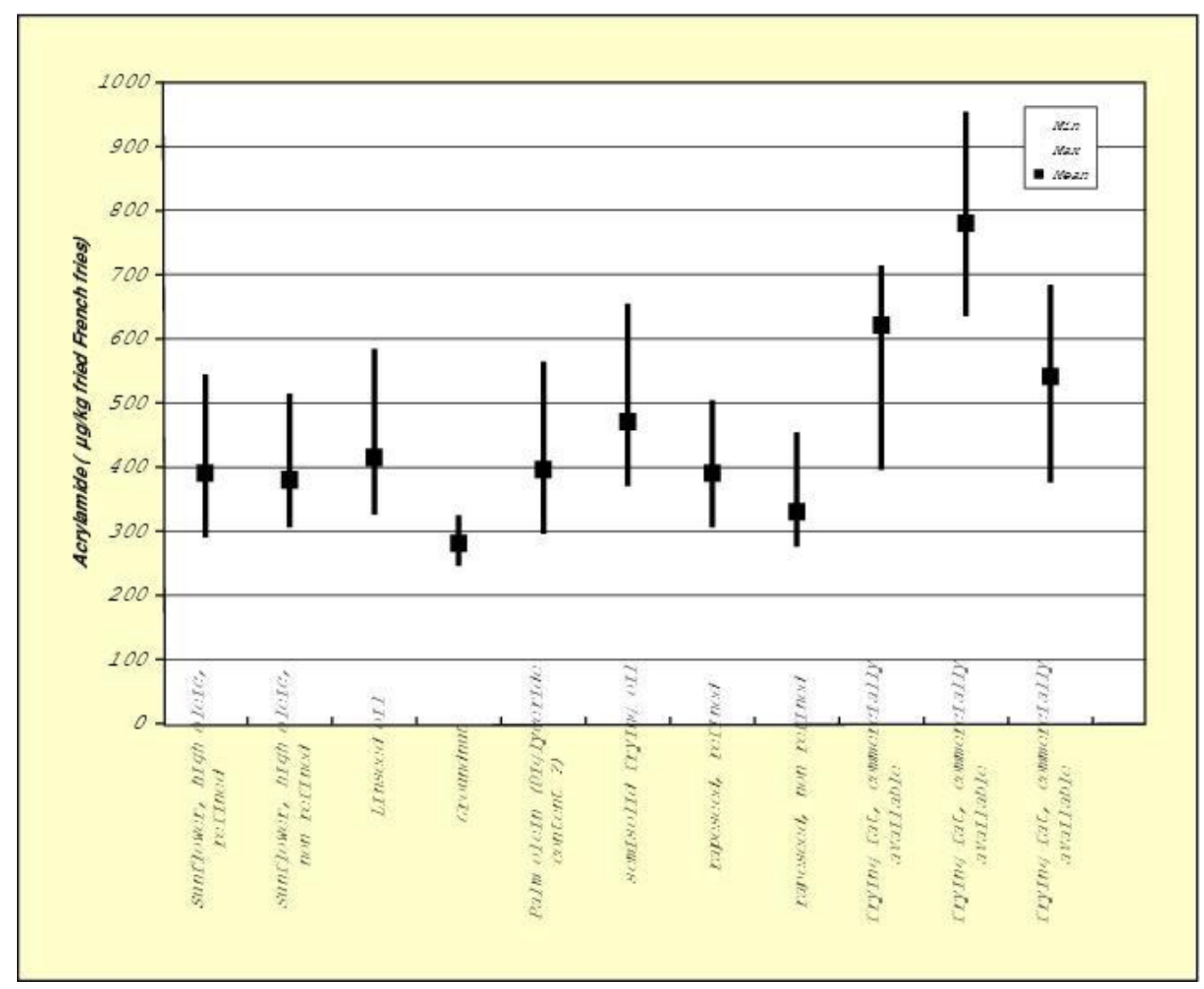

Figure 4. Acrylamide formation in different fats and oils during deep-frying at $170{ }^{\circ} \mathrm{C}$ (data source MATTHAEUS [11]). 


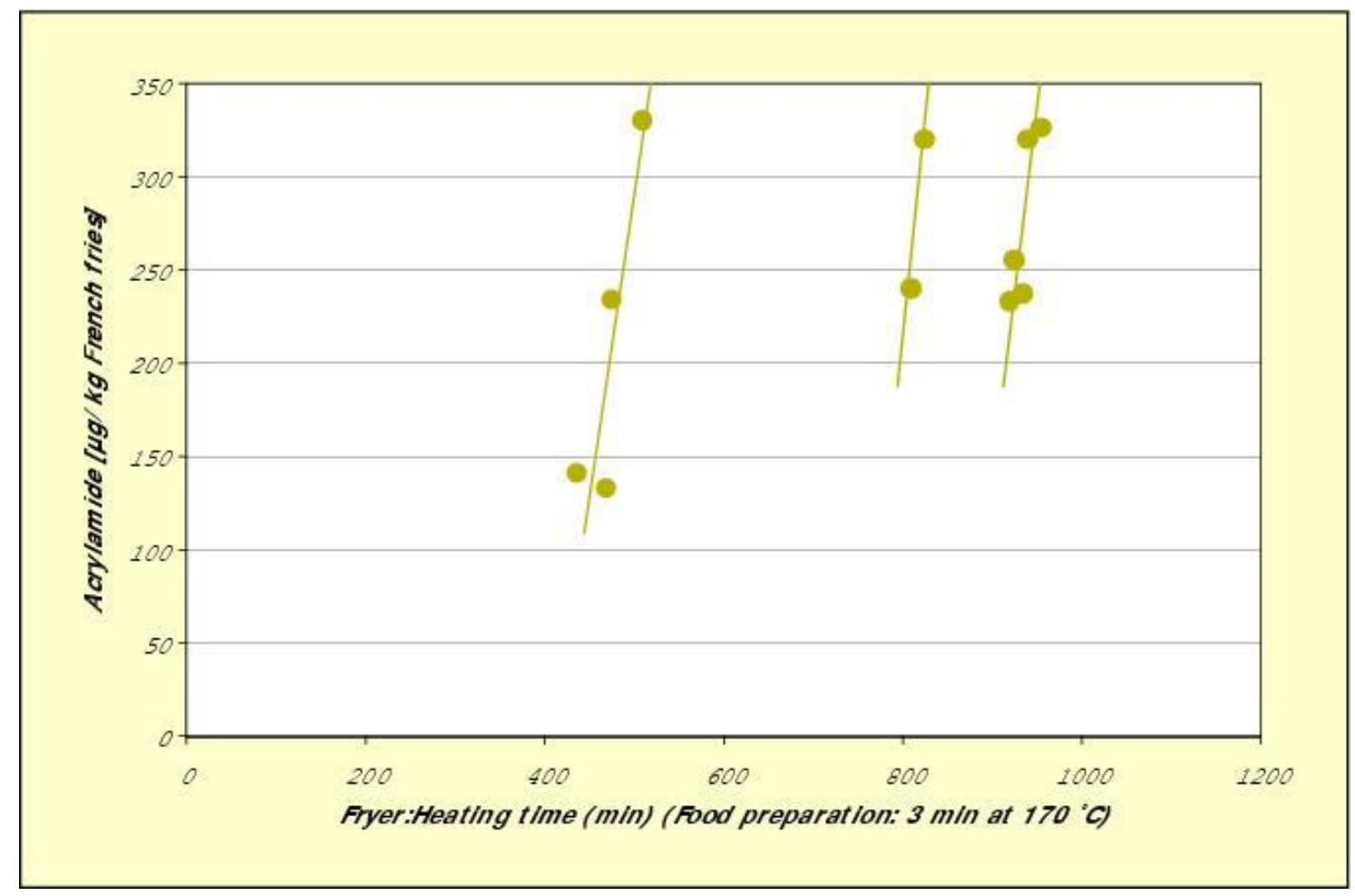

Figure 5. Accelerated formation of acrylamide in French fries with increasing number of batches (deep-frying oil : part. hydr. rape seed oil with $1.5 \mathrm{mg} / \mathrm{kg}$ Dimethylpolysiloxane = DMPS (E900).

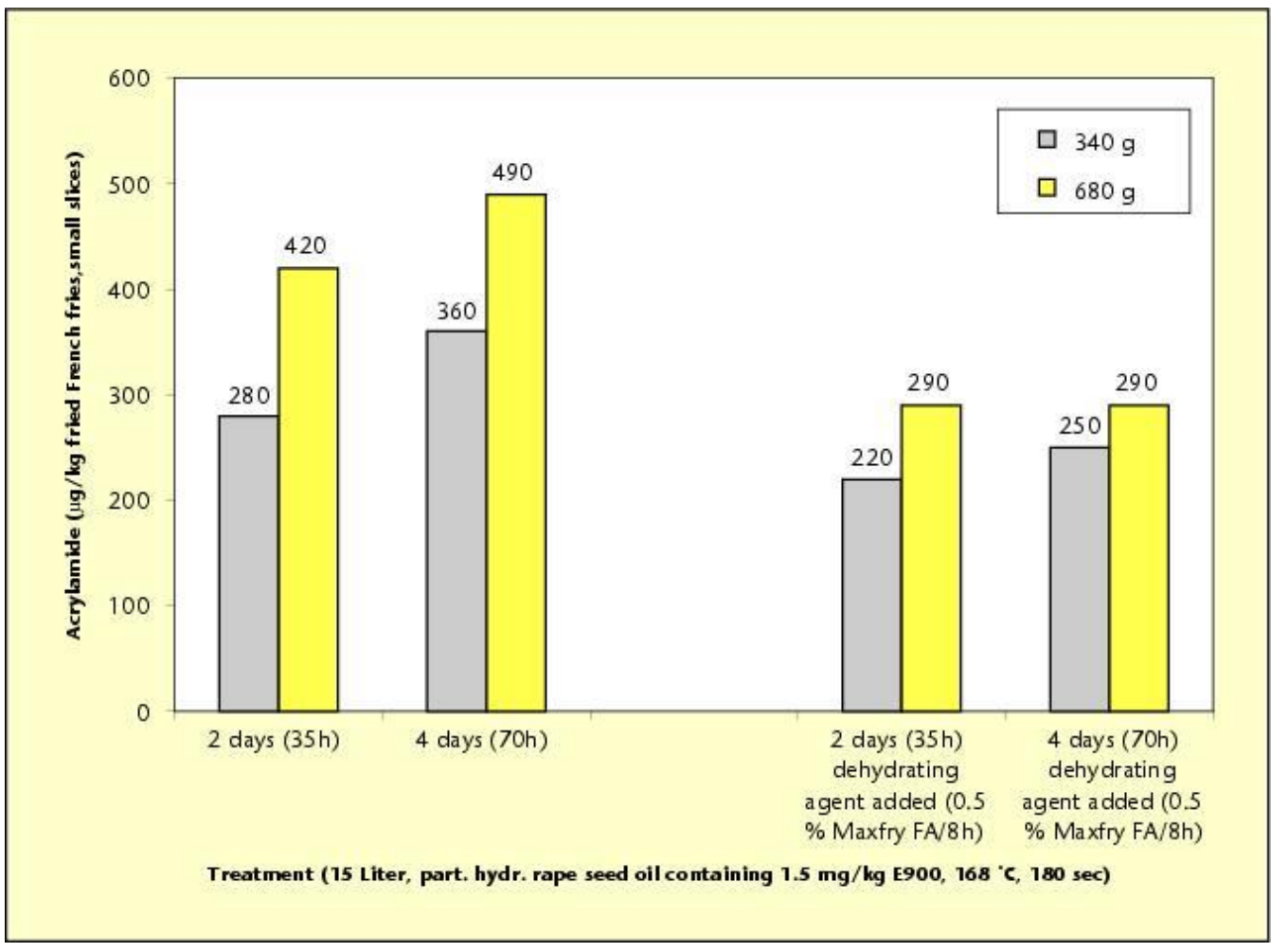

Figure 6. Reduced formation of acrylamide in French fries by special additives. 


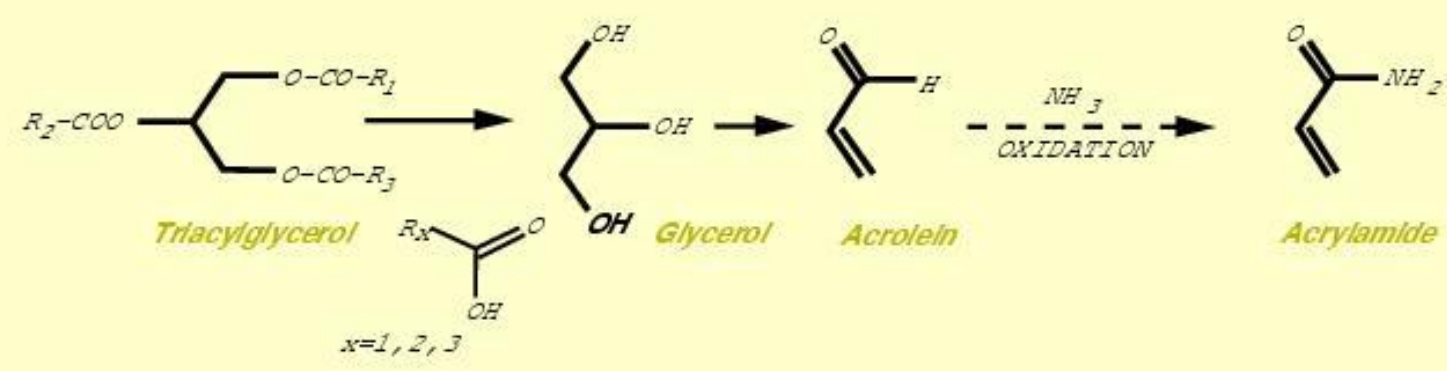

Figure 7a. Forming of acrylamide by hydrolysis of triacylglycerol.

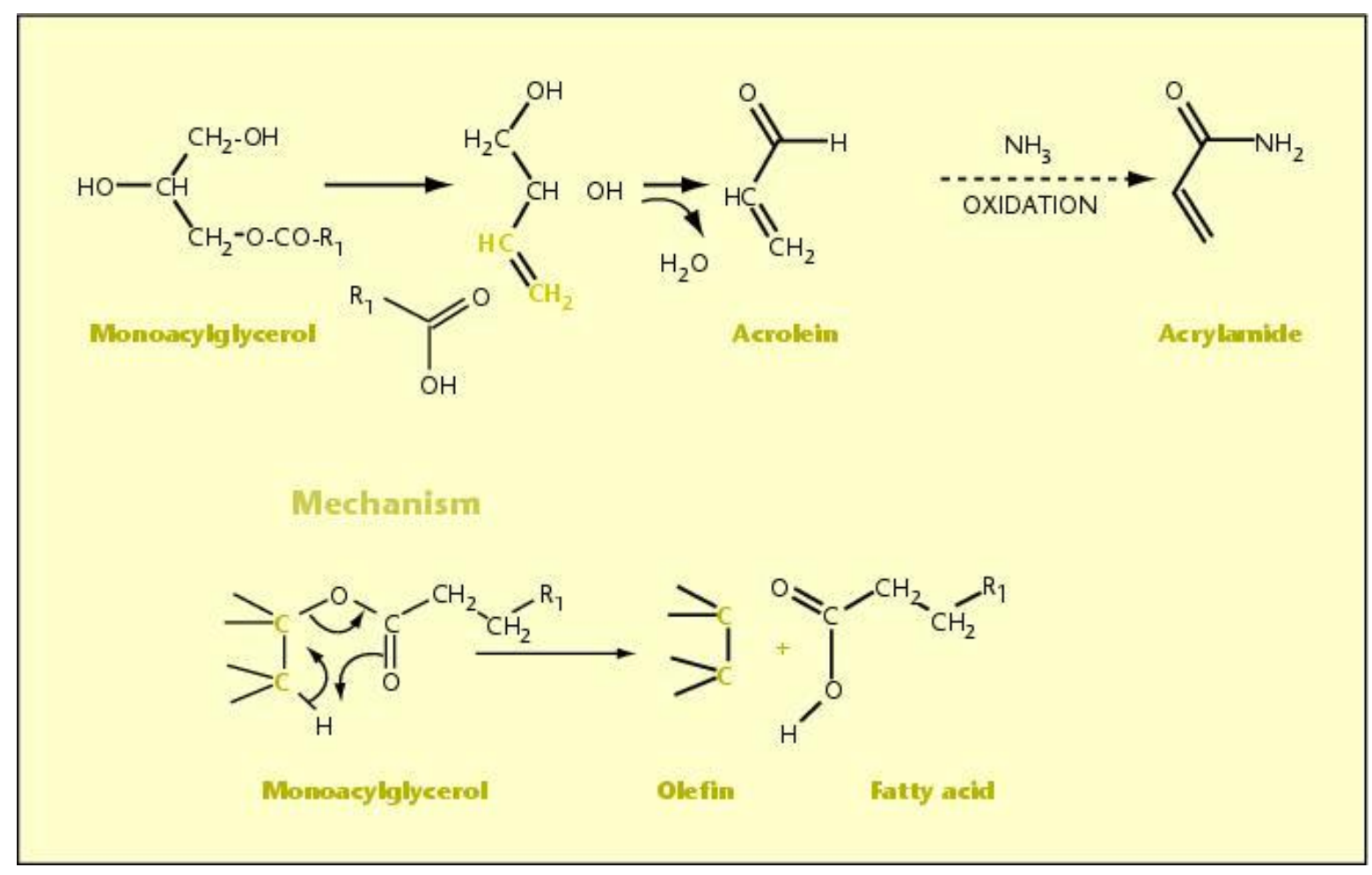

Figure 7b. Forming of acrolein by a cyclic mechanism from monoacyglycerol. 


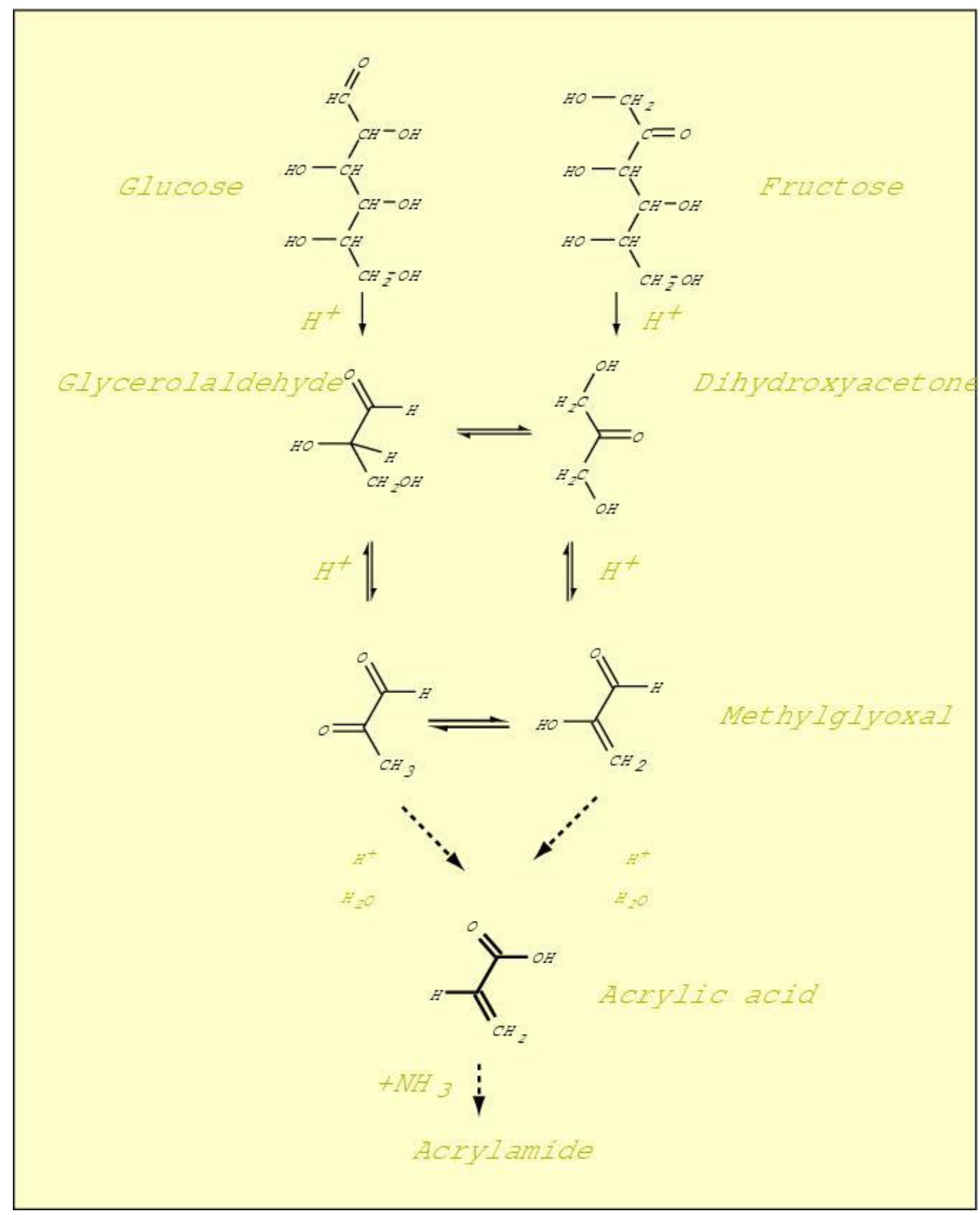

Figure 7c. Forming of acrylamide from reducing sugars via acrylic acid. 


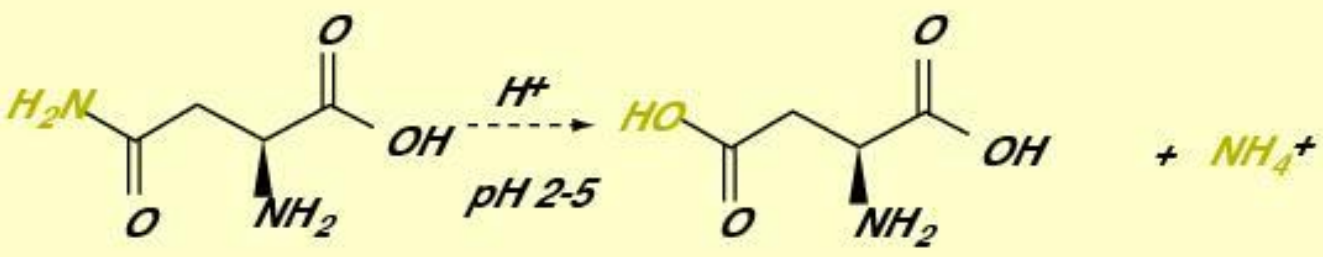

\section{Asparagine}

\section{Aspartic acid}

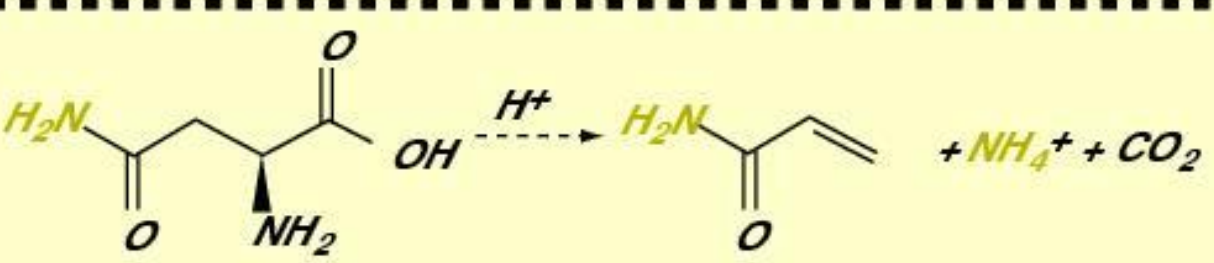

Figure 7d. Formation of acrylamide from asparagine. 